\title{
The Nude Mouse as Model for Liver Deficiency Study and Treatment and Xenotransplantation
}

\author{
Isabelle Vidal ${ }^{1,2}$ and Lysiane Richert ${ }^{1,3}$ \\ ${ }^{1}$ Faculté de Médecine et de Pharmacie, EA 3921, IFR 133, 25030 Besançon, France \\ ${ }^{2}$ Unit of Pediatric Surgery, Geneva University Hospital, 1211 Geneva, Switzerland \\ ${ }^{3}$ KaLy-Cell, 20A rue du Général Leclerc, 67115 Plobsheim, France \\ Correspondence should be addressed to Lysiane Richert, l.richert@kaly-cell.com \\ Received 25 May 2012; Revised 13 August 2012; Accepted 7 September 2012 \\ Academic Editor: Shay Soker
}

Copyright ( $\odot 2012$ I. Vidal and L. Richert. This is an open access article distributed under the Creative Commons Attribution License, which permits unrestricted use, distribution, and reproduction in any medium, provided the original work is properly cited.

\begin{abstract}
We aimed at reviewing the various uses of Nude mouse for the development of liver deficiency models and evaluation of efficacy of hepatic cell xenotransplantation. The first part records the large range of liver deficiency models that can be developed in Nude mice: surgical partial hepatectomy, acute toxic liver deficiency, chronic cirrhosis, and transgenic liver injury. The second part tackles the outcome of rat hepatocyte as well as human cell transplantation, both mature hepatocyte and hepatic progenitor, into Nude mouse submitted to liver injury. Results are discussed and compared to other available immunodeficient mouse models. The issue of humanized liver creation is also addressed. Altogether, these results show that Nude mouse appears to be a suitable small animal model to expand our insight into liver cell engraftment and regeneration.
\end{abstract}

\section{Introduction}

Orthotopic liver transplant remains the treatment of choice for fulminant or acute liver failure and end-stage chronic liver deficiency. Etiologies of these liver failures are numerous, ranging from metabolic liver diseases, infectious causes, nonlife compatible large hepatectomy to alcohol hepatic pathology and others. Most remain symptomatic treatments, and liver transplant is often the only key solution. Unfortunately, the increased need for organ transplantation is met by a lack of organ donors. Some surgical techniques such as living donor procedure [1] or cadaveric donor liver split sharing between two recipients [2]; as well as bioartificial hepatic support [3] can partly alleviate this shortage.

The lack of therapeutic alternatives led scientists to develop cell transplantation research. Cell transplantation could not only replace solid organ transplantation for the medical indications listed above but also it could, in addition, be proposed for gene therapy applications, in which organ transplant is a procedure too heavy to be ethically accepted such as congenital deficiency of a liver metabolic pathway, that does not impair liver function.
We first focused on the evaluation of adult hepatocyte transplantation for treatment of liver deficiency by cell therapy $[4,5]$, since it presented many attractive aspects when compared to organ transplant: better availability of cells, less invasive surgery, redo possibility, and lesser cost. It could also become a bridge between fulminant liver deficiency and organ transplant, to gain time before getting an organ suitable for transplantation $[6,7]$.

More recently, liver stem cells appeared to also be good candidates for transplantation, with the advantage of being maintained longer in culture than mature hepatocytes which lose their functions after a few days and being easily harvested from various human sources (adult, embryonic and fetal liver, and nonhepatic mesenchymal tissue, as well as induced pluripotent stem cells (iPS)) $[5,8,9]$.

To optimize understanding of cell transplantation mechanisms, small animal models were created to allow the study of cell engraftment conditions and mechanisms of liver regeneration.

On the other hand, the major species differences in the metabolism of drugs require metabolism and toxicity studies using models as close as possible to humans. In addition 
to the current gold standard in vitro approach of cultured adult human hepatocytes for the prediction of in vivo hepatic metabolism, pharmacokinetic and toxicity in humans [10, 11 , the use of in vivo approach of animals with humanized livers have been explored [12-14]. Furthermore, viral pathobiological studies, that is, hepatitis $\mathrm{B} / \mathrm{C}$ viral infections and treatment that are not possible on primary human hepatocyte in culture since the cells become nonpermissive for $\mathrm{HB} / \mathrm{CV}$ after plating, have been made possible with the development of animal models with humanized livers [1517].

For these two research area applications, immunosuppressed animal models, that would bear xenogenic cell transplantation without immunosuppressive drug, needed to be developed. In order to allow the evaluation of treatment of liver deficiency, an additional request of animal models was that they could be submitted to treatments mimicking human clinical liver pathologies requiring cell transplant therapy.

The vast majority of research began with murine models, such as immunodeficient mice, with normal liver, or undergoing liver failure (by toxic liver injury, partial hepatectomy, or transgenic modification) and was tested for xenogenic hepatocyte transplantation, at first murine-murine models secondarily extended to human-murine transplantation (Table 1).

A variety of immunosuppressed mouse models have been developed [32]. For the evaluation of liver deficiency treatment via cell transplantation, the most commonly used models are the SCID mouse, lacking functional $\mathrm{T}$ and $\mathrm{B}$ cells, and RAG2 mouse (transgenic mouse with recombinant activation gene-2 (RAG-2)s), which lack mature $\mathrm{T}$ and $\mathrm{B}$ lymphocytes [33]. Literature reports less numerous studies with Nude mice. Yet, this athymic mouse with high deficit of mature $\mathrm{T}$ cells due to a Fox gene family mutation (Foxn1 $[34,35])$ is a more robust model than SCID or RAG2 mouse, and it can be bred in less immunoprotective environment $[36,37]$.

Nude mice have been used since 1968 [32] to study xenogenic tumor development [38-42], imaging testing [43], or gonadal grafts [44].

\section{Nude Mouse Is Successful for Induction of Liver Injury}

In murine models, different liver injuries can be performed, to induce hepatic deficiency comparable to human's one: (1) surgical, by extensive partial hepatectomy; (2) toxic by administration of carbon tetrachloride $\left(\mathrm{CCl}_{4}\right)$ (that can also act on transplanted hepatocyte because of its long half- life) [45-47], by D-Galactosamine that generates at low dose an apoptosis and at higher dose a necrosis and fulminant hepatitis [48], by retrorsine [49-51] that suppresses hepatocyte proliferation, or by Fas-ligand agonist that will trigger cell apoptosis on mouse hepatocyte, such as Jo2 antibody treatment [52-57]; (3) radiotherapy was also used to block liver regeneration $[6,58]$. But, the most growth selective advantage model used is (4) transgenic mice, with natural liver injury by hepatotoxicity of metabolism disorders. There are two main models: $\mathrm{uPA}^{+/+}$(uroplasminogen activator) mouse $[59,60]$ and $\mathrm{Fah}^{-/-}$[61] (fumarylacetoacetate hydrolase) mouse. Interestingly, we have found that most of these liver injuries can be applied to Nude mice.

2.1. Surgical Partial Hepatectomy in Nude Mouse. In our experience [62], and in contrast to the more resistant wildtype Balb/c mice, Nude mice did not survive $70 \%$ partial hepatectomy performed according to the technique of Higgins and Anderson [63] and died within $24 \mathrm{~h}$ following the surgery. Our finding is not in accordance with the report of Strom et al. [64] referring to a high survival rate of Nude mice submitted to two third partial hepatectomy. Forty percent partial hepatectomy was successful and consisted, after median laparotomy, in the resection of the left lateral liver lobe of Nude mice, after ligation using 3 to 5 titanium 3-mm clips for stapling (LIGACLIPrm, Ethicon, France). Hemostasis was performed by dabbing the bloody cut surface with caution using a hemostatic cellulose gauze (SURGICELrm, Johnson \& Johnson, France), with removal of this gauze, to decrease postoperative mortality [62]. We recommend the surgery not to exceed $5 \mathrm{~min}$. After partial hepatectomy, animals were warmed up for at least $20 \mathrm{~min}$ under heating lamp to restore their preoperative body temperature and were supplemented for $24 \mathrm{~h}$ with $20 \%$ glucose in drinking water.

Serum ALT increased $(\times 2$ compared with the day 0 value $)$ on day 1 following surgery and returned to basal levels within 3 days. Histological features of liver regeneration, Ki67 and caspase 3 expression, proved that both mechanisms of apoptosis and cell proliferation coexist without any necrotic stage during liver regeneration [62]. This confirms literature data [65]. Restoration of liver mass occurred within 10 days.

\subsection{Acute Toxic Liver Injury in Nude Mouse}

2.2.1. Thioacetamide (TA). Various doses were tested on Nude mice, with a $20 \%$-mortality at day 10 following an injection of $1700 \mathrm{mg} / \mathrm{kg}$ and $100 \%$-mortality at 48 hours with a $2000 \mathrm{mg} / \mathrm{kg}$ TA dose. Serum ALT values reached 20 times the day 0 values 24 hours after a $1700 \mathrm{mg} / \mathrm{kg}$ TA injection to Nude mice; then a progressive return to basal values was observed, which was complete on day 7 . This correlated with a massive liver necrosis (up to one-third of liver), maximal at 24 hours and then decreasing with normal histology at day 10 [62].

2.2.2. Jo2 Single Dose. Fas antigen is a cell surface receptor that mediates cell apoptosis when stimulated. Jo2 antibody is a Fas-ligand agonist and acts by stimulating Fas antigen and cell apoptosis. Jo2 is mouse specific; thus, it does not trigger apoptosis of other species, and it acts mainly on hepatocyte [66]. Heart, lung, bone marrow, and kidney express Fas, but are not sensitive to Fas apoptosis [67].

The specific anti-mouse Fas monoclonal antibody Jo2 was injected at $125,250,375$, or $500 \mu \mathrm{g} / \mathrm{kg}$ IP dose to Nude mice, with higher sensitivity and mortality compared to Balb/c mice [62]. This anti-Fas antibody Jo2 was proven to induce fulminant hepatic failure in mice after a single 


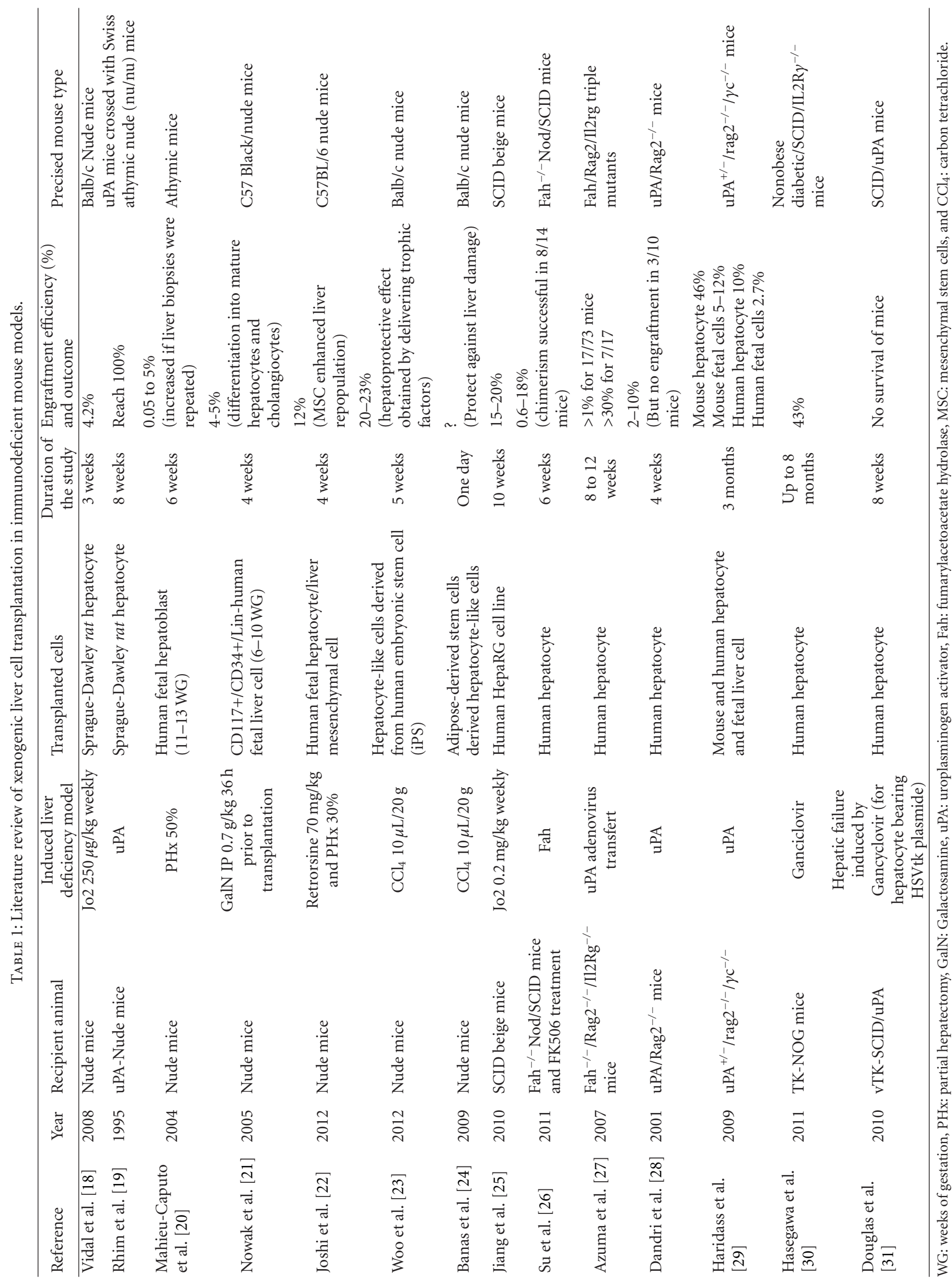




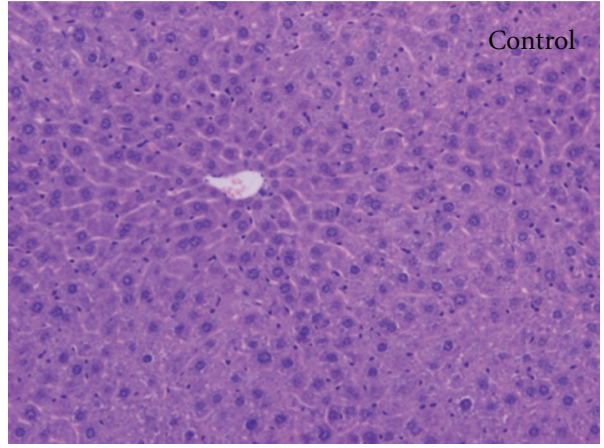

(a)

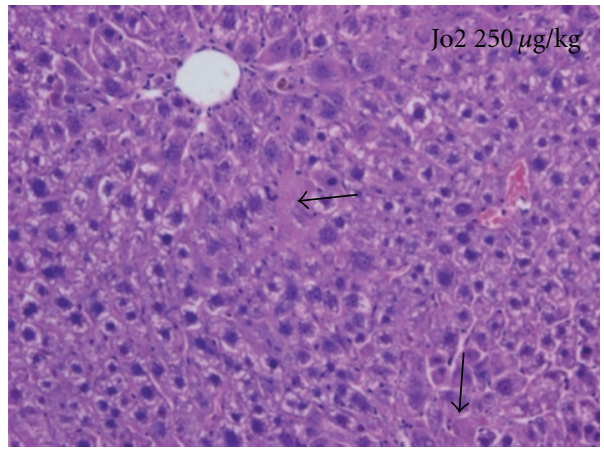

(c)

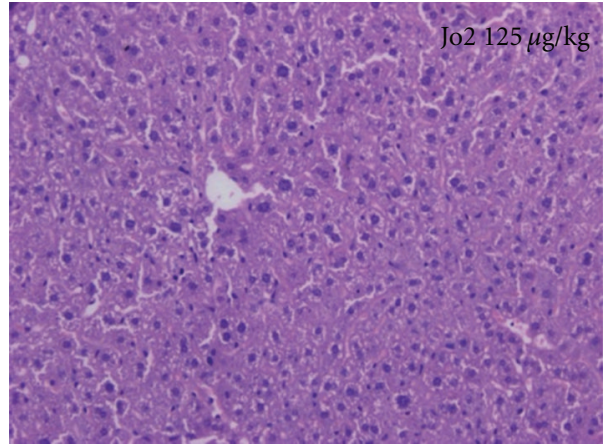

(b)

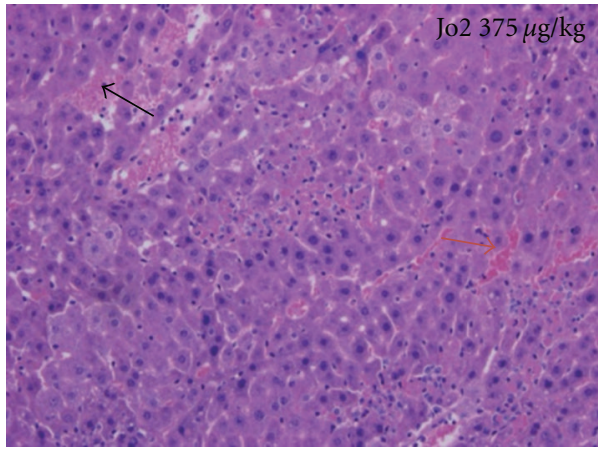

(d)

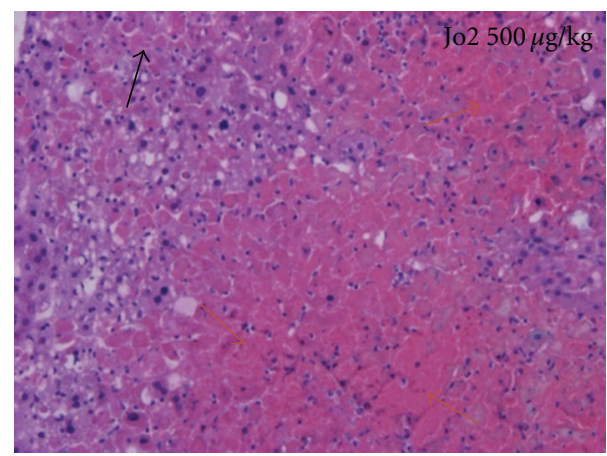

(e)

FIGURE 1: Nude mouse liver histology after hematoxylin and eosin staining, in mouse control (a) and after a single Jo2 injection of $125 \mu \mathrm{g} / \mathrm{kg}$ (b), $250 \mu \mathrm{g} / \mathrm{kg}$ (c), $375 \mu \mathrm{g} / \mathrm{kg}$ (d), and $500 \mu \mathrm{g} / \mathrm{kg}$ (e). Photomicrographs were taken using Olympus DP70 microscope with an original magnification of 100x. Black and blue arrows indicate apoptotic foci and necrotic foci, respectively.

injection [68-70], characterized by an elevation of serological ALT for the first three days. The survival rates correlated with histological observations of liver necrosis. Histologically, massive necrosis (with less than $5 \%$ of healthy parenchyma) was observed in Nude mice at $500 \mu \mathrm{g} / \mathrm{kg} \mathrm{Jo2.} \mathrm{Severe}$ panlobular and panacinar necrosis already occurred at $375 \mu \mathrm{g} / \mathrm{kg}$ Jo2 on day 1 after treatment (Figure 1). Liver deficiency injury was a dose-dependent effect, and it was reversible within 10 days. The regenerative capacity of the liver was thus retained after Jo2 injection, making its use attractive for studying the efficacy of hepatocyte transplantation [62].

2.2.3. D-Galactosamine (GalN). Nowak et al. [21] described a single intraperitoneal administration of $0.7 \mathrm{~g} / \mathrm{kg}$ body weight D-Galactosamine, eventually followed 36 hours later by cell transplantation. The mortality rate was $62 \%$ in absence of transplantation, occurring in the first 72 hours.

2.2.4. Carbon Tetrachloride $\left(\mathrm{CCl}_{4}\right)$. $\mathrm{CCl}_{4}$ was also used to induce acute liver deficiency in Nude mouse [23, 24] by intraperitoneal injection of $100 \mu \mathrm{L} / 20 \mathrm{~g}$ body weight of $10 \%$ $\mathrm{CCl}_{4}$ in olive oil.

2.3. Induction of Liver Cirrhosis in Nude Mouse. We succeeded in inducing cirrhosis in Nude mice, by repeated thioacetamide injections at $200 \mathrm{mg} / \mathrm{kg}$ of body weight, three times a week for 14 weeks [62]. Macroscopically, the liver of Nude mice presented a slightly rough surface after 58 weeks of treatment. Nude mice exhibited a spectacular 


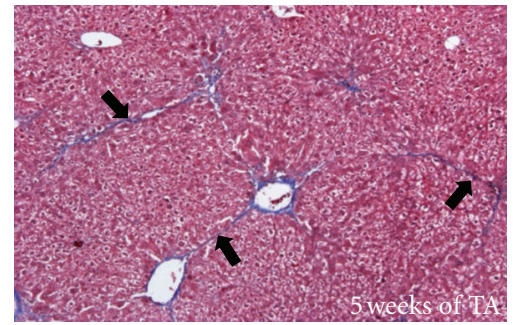

(a)

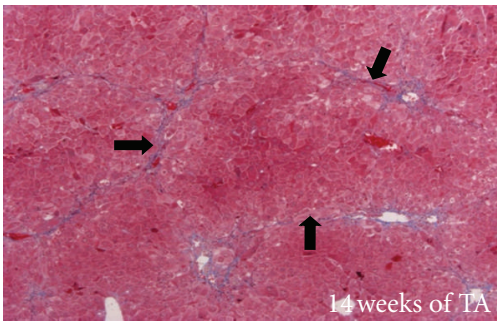

(b)

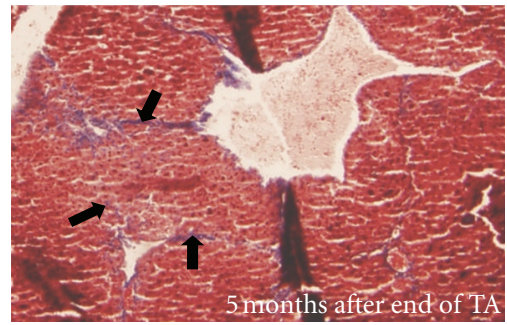

(c)

FIGURE 2: Liver histology after trichrome staining of Nude mice 5 weeks (a) and 14 weeks after the beginning of the thioacetamide cirrhogenic treatment and 5 months after the end of the 14-week-long treatment (c). Black arrows indicate fibrous extension. Photomicrographs were taken using Olympus DP70 microscope with an original magnification of 40x.

fibrosis and onset of cirrhosis from 5 weeks of treatment. Histological features showed accentuated lobulation, with some nearly complete rings of connective tissue surrounding lobules (Figure 2). Micronodular cirrhosis was observed after 14 weeks. Ki67-positive cells were more numerous after 14 weeks of treatment compared with 5 weeks of treatment, reflecting intense proliferation of hepatocytes. Induction of cirrhosis in Nude mice was found to reverse to fibrosis within 5 months after cessation of the treatment [62].

2.4. $\mathrm{uPA}^{+/+}$(Uroplasminogen Activator) Transgenic Nude Mouse. uPA-Nude mice were used by Rhim et al. [19] by crossing Alb-uPA transgenic mice with athymic nu/nu mice. This $\mathrm{uPA}^{+/+}$mouse model presents an activation of the transgene that expresses uroplasminogen activator under the control of an albumin promoter. This overexpression of uPA causes liver injury with accumulation of hepatotoxic substrate and progressive depletion of hepatocytes, neonatal bleeding, associated to kidney disease. The homozygous mice die from liver deficiency, unless they received safe non-uPA hepatocyte transplantation. In heterozygous mice, population of non-uPA hepatocyte can spontaneously develop and repopulate the liver in about 8 weeks $[59,60]$. It has been reported that hepatocytes without uPA expression, when transplanted, have a growth advantage over the hepatocytes with transgenic $\mathrm{uPA}^{+/+}$leading to cell death $[59,60,71,72]$.

\section{5. $\mathrm{Fah}^{-/-}$(Fumarylacetoacetate Hydrolase) Transgenic Nude} Mouse. The transgenic mouse model $\mathrm{Fah}^{-/-}$is a mutant mouse deficient in tyrosine catabolic enzyme fumarylacetoacetate hydrolase, corresponding to clinical model of human type 1 tyrosinemia. This pathology results in progressive hepatocellular injury and mouse death in a few weeks. This liver injury can be prevented by a drug: 2-(2-nitro-4-trifluoromethylbenzoyl)-1,3-cyclohexanedione (NTBC), usually put in animal drinking water [61]. Breeding is easier than for $\mathrm{uPA}^{+/+}$mice; there is no renal deficiency, and transplant can be performed at any time [27]. Azuma et al. used $\mathrm{Fah}^{-/-}$Nude mouse model to test for human hepatocyte transplantation [27].

So, Nude mouse is a suitable small animal model in which it is possible to induce different types of hepatic deficiencies, from acute fulminant hepatitis to chronic cirrhosis, including surgical partial hepatectomy, and inborn inherited metabolic disorders. It also presents the advantage of an inborn immunosuppressed status, which could allow for xenogenic organ or cell transplantation. Thus, it was developed with different hepatic mature and progenitor cell transplantation, isolated from rat and human livers.

\section{Nude Mouse Is a Successful Xenotransplantation Model for
the Evaluation of the Efficacy of
Cell Therapy}

Before human clinical application of hepatocyte transplantation, it is of high importance to evaluate efficacy of cell transplantation on small animal models, in clinical situation.

\subsection{Nude Mouse Is a Successful Murine Xenotransplantation} Model. As reported in literature [49, 73], engraftment of hepatocyte into recipient livers is largely favored if a selective advantage (i.e., existence of growth and proliferation difference) between donor and recipient hepatocytes does exist. This was confirmed in Nude mouse model transplanted with rat hepatocytes: on healthy liver, mature hepatocyte could engraft but with a very limited proliferative activity, and engraftment after $40 \%$ hepatectomy in Nude mice liver parenchyma did not differ from non-operated control Nude mice [62]. These results could be due to the time difference between transplanted rat hepatocyte and mouse hepatocyte proliferation, the peak of DNA synthesis being observed 24 hours after partial hepatectomy in the rat and 48 hours after partial hepatectomy in the mouse [74]. Neither a single dose of Jo2 pretransplantation treatment nor TA-liver injury improved rat hepatocyte engraftment [62].

Thus, we interpreted this lack of repopulation as a deficit of selective advantage [18]. In literature, several studies used a growth selective advantage by repeating recipient hepatocyte apoptosis with Jo2 while transplanting Jo2 resistant cells: for example, $\mathrm{BCl}-\mathrm{XL}$ overexpressing mouse hepatocytes (i.e., resistant to jo2) transplanted in a CBA mouse resulted in a $4 \%$ mean implantation rate (range from 2 to 6\%) [55], and $\mathrm{BCl} 2$ over-expressing mouse hepatocytes, more resistant to Jo2 than BCl-XL cells [75], resulted in a mean $30 \%$ of repopulation (ranging from 1 to 30\%) [76]. We hypothesized 


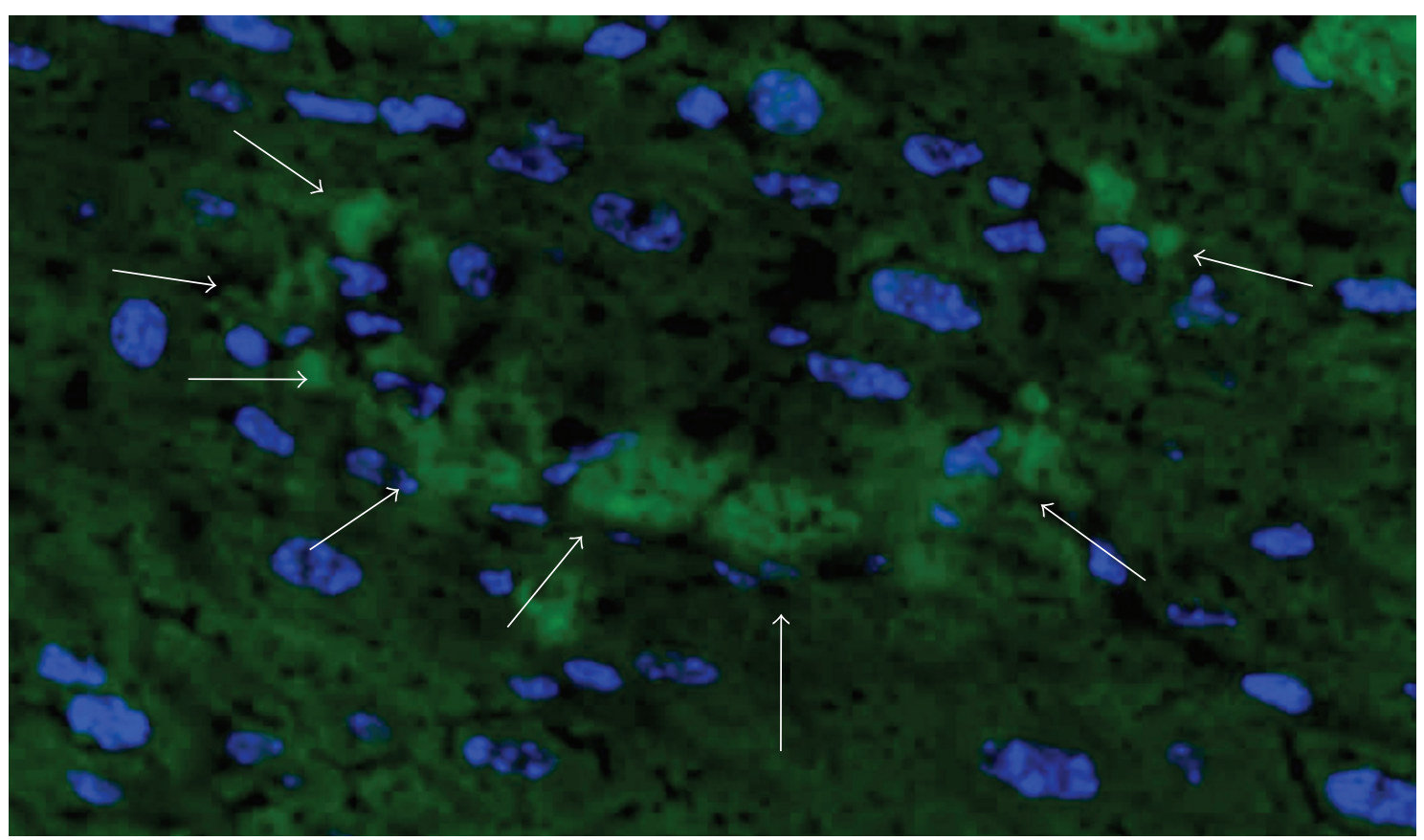

FIGURE 3: Immunodetection of engrafted rat hepatocytes in Nude mouse liver (original magnification $\times 40$ ), 21 days after cell transplantation, treated weekly with repeated doses of Jo2 $(250 \mu \mathrm{g} / \mathrm{kg}$ ). Blue: Nuclei staining (Hoechst 33342), green: positive CMH class I signal, white arrow: rat hepatocyte.

that because rat hepatocytes were resistant to Jo2 drug they would get this selective advantage, on a Jo2 treatment repeated model [18]. In fact, repeated administration of Jo2 maintained liver deficiency in Nude mice. We observed [18] that the effects of each weekly Jo2 challenge were equivalent during a 3-week experiment: after each $250 \mu \mathrm{g} / \mathrm{kg}$ body weight dose of Jo2, liver injury could be proven by the increases in serum ALT levels following $24 \mathrm{~h}$. Routine histology showed panlobular necrosis $24 \mathrm{~h}$ after the last Jo2 administration, identical to the necrosis seen $24 \mathrm{~h}$ after the first Jo2 administration, meaning liver remained sensitive to anti-Fas antibody. Three weeks after transplantation, engraftment rate was determined by immunodetection of the transplanted rat hepatocytes using an anti-rat MHC type I antibody (Figure 3). Engraftment of xenogeneic rat hepatocytes, when transplanted to Nude mice presenting an acute liver failure induced by a single sublethal injection of this anti-Fas antibody, could be improved when mice were further submitted to a weekly repeated Jo2 apoptosisinducing treatment. In the latter case, engraftment was increased about sevenfold (about $2.4 \%$ of repopulation). On genomic analysis comparing Jo2 single dose versus weekly repeated Jo2 treatment in Nude mice receiving rat hepatocytes, the altered pathways suggested a blockade of cell cycle and proliferation (upregulation of cell cycle regulation and downregulation of circadian transcripts), activation of interferon- $\gamma$ pathways, activation of antigen-presenting cells that probably reflects the immune system activation secondary to hepatocyte necrosis and liver injury, and metabolic pathway inhibition confirming liver injury. This overall transcriptome profile might correspond to a selective advantage model where cell cycle blockade occurs in mouse hepatocytes submitted to weekly Jo2 treatment, while natural Jo2 resistance of rat hepatocytes allows them to proliferate [18].

Apart from toxic liver injury, Rhim et al. [19] transplanted rat hepatocytes into a transgenic $\mathrm{uPA}^{+/+}$-Nude mice, with high rate (near 100\%) of repopulation achieved in 6 to 14 weeks. Presence of rat hepatocytes was confirmed by histology, immunostaining, and rat transferrine measurement.

Weglarz and Sandgren used the same model to determine that hepatocyte entry into DNA synthesis depends on each species and is not influenced by nature of animal recipient and engraftment [74].

For rat hepatocyte transplantation model, Nude mouse seems to be efficient, with complete repopulation in transgenic $\mathrm{uPA}^{+/+}$model, and less important engraftment in other hepatic injury models, comparable to results obtained in similar allogenic models.

\subsection{Nude Mouse Is a Suitable Human Xenotransplantation Model to Study Engraftment Mechanisms}

3.2.1. Human Mature Hepatocyte Transplantation. We recently demonstrated [77] that human hepatocyte transplantation into recipient Nude mice submitted to sublethal and lethal repeated Jo2 liver injury could present a hepatoprotective effect, despite a very poor engraftment rate, lasting up to 7 weeks after transplant. Genomic analysis correlated this lack of engraftment to an absence of selective advantage, cumulated with a paradoxical increased survival rate linked to stimulation of host cell proliferation. These genomic 
results are in contradiction with those observed with the same treatment protocol and rat hepatocyte transplantation [18].

This hepatoprotective effect of mature hepatocyte transplantation was also described by Banas et al. [24]. They generated in vitro human adipose-derived stem cells- (ASC-) derived hepatocytes, and they transplanted these hepatocytelike cells into female Nude mouse 24 hours after an intraperitoneal injection of $10 \mu \mathrm{L} / 20 \mathrm{~g}$ of $\mathrm{CCl}_{4}$. Woo et al. [23] transplanted hepatocyte-like cells derived from human embryonic stem cell (iPS) to Nude mice and found an hepatoprotective effect, not only on engrafted nodules but also on places far from them, which could be linked to delivered trophic factors (same effect observed after injection of secreted proteins alone).

Commenting on the very poor engraftment in the repeated Jo2 Nude mouse model [18], it is of common knowledge that even in more immunosuppressed and transgenic models, an important rate of failure of chimerism has been observed. For example, Dandri et al. [28] described a $70 \%$-success rate to raise minimal human hepatocyte engraftment in a $\mathrm{uPA}^{+/+} / \mathrm{RAG}^{-/-}$mouse liver, with an allor-none response for human hepatocyte engraftment. It means that in one-third of their mice, human cells did not engraft at all. They correlated this $30 \%$ - failure result with time of prolonged warm ischemia and with poor viability of transplanted cells. These results were confirmed in a model of uPA/SCID mouse where engraftment was successful in a median of $22 \%(0-87 \%)$ of animals, linked with donor age and warm ischemia [78]. Other authors also report failure of chimerism in human-murine models [79].

3.2.2. Human Liver Progenitor Cell Transplantation. Human fetal liver progenitor cells are able to engraft in Nude mouse model, after retrorsine injection followed three weeks later by $30 \%$-partial hepatectomy challenging [22], 50\%-partial hepatectomy alone [20], or galactosamine-induced liver deficiency [21]. Engraftment rate range from $0.05-10 \%$ [20] and $4-5 \%$ [21] to $5-12 \%$ [22]. Repopulation yield could be triggered by cotransplantation with fetal liver mesenchymal cells [22] or repeated liver biopsies [20].

Interestingly, in these Nude mouse models, human fetal liver progenitor cells not only demonstrate proliferation but also differentiation into both mature hepatocyte and cholangiocyte pathways. Four to six weeks after transplantation, clusters of cells have developed, that have lost their progenitor markers and display morphological and immunohistological markers of mature cells [20-22].

We can compare these results to those obtained by transplanting HepaRG naturally immortalized human liver cell line into SCID/beige mice (SCID-NK cell deficient mice) that were thereafter (first injection began at day one posttransplantation) treated with $0.2 \mathrm{mg} / \mathrm{kg}$ Jo2 once a week for 10 weeks [25]. HepaRG cells are bipotent progenitor and in vitro express biologic functions at the same level as primary human mature hepatocytes. They engrafted in Jo2treated mice liver with a 15-20\% repopulation of recipient liver, which is comparable to results obtained with fetal hepatoblast transplanted into Nude mice [22].
The results altogether suggest that it is of most importance to pay attention to chronology (to avoid transplantation preceding liver injury), to be the closest to human clinical scene.

\section{Nude Mouse Is Not a Suitable Xenotransplantation Model for the Creation of Humanized Liver}

Most of maximal human cell engraftment was described on two transgenic models with highly immunosuppressed mouse models, $\mathrm{uPA}^{+/+}$mice and $\mathrm{Fah}^{-/-}$mice. This engraftment could become sufficient to talk of "humanized liver," with human hepatic functions and human pharmacological proprieties [12-14, 80].

The first is the $\mathrm{uPA}^{+/+}$mouse model. To our knowledge, there was no publication of human liver cell transplanted in a Nude mouse uPA model.

The second transgenic $\mathrm{Fah}^{-/-}$mouse model was used by Azuma et al. [27] in $\mathrm{Fah}^{-/-}$Nude mice model to create humanized liver, but they did not obtain sufficient human cell engraftment in this model and had to use a more immunosuppressed transgenic model $\left(\mathrm{Fah}^{-/-} / \mathrm{Rag}^{-/-}\right.$$/ \mathrm{I} 12 \mathrm{rg}^{-/-}$- mice) reinforced by uPA-adenovirus administration intravenously $24-48$ hours before human hepatocyte transplantation, associated to NTBC withdrawal over five days after transplantation.

To our knowledge, no success in humanized livers in Nude mice has been reported, most likely because of an insufficient immunosuppression of this mouse.

In other $\mathrm{uPA}^{+/+}$immunosupressed mouse models, such as Rag2 $2^{-/-}$mice, human hepatocytes can engraft, although at lower rate than murine hepatocytes $[79,81]$. In such a model, Dandri et al. [28] reported 8 weeks after human hepatocyte transplantation a 2 to $10 \%$ of repopulation by human cells. In the $\mathrm{Fah}^{-/-}$mouse model, human hepatocytes could repopulate $\mathrm{Fah}^{-/-} / \mathrm{Rag}^{-/-} / \mathrm{Il} 2 \mathrm{rg}^{-/-}$mouse liver with a range from 5 to $34 \%, 12$ weeks after transplant [26].

But these two models have specific disadvantages, directly linked with their concept; $\mathrm{uPA}^{+/+}$mice, because of their inborn metabolic abnormally, have a poor breeding efficiency, a quite narrow window in time to perform transplantation (on neonatal age, between 1 to 3 weeks of age, before they die of severe bleeding), and a renal disease that still exists despite hepatocyte transplantation $[19,27,59,60]$. They can return to wild type by inactivation of the gene [59]. Moreover, there is a continuous and progressive hepatic parenchyma injury, possibly via activation of plasminogen and modified activity of matrix metalloproteinase: thus, this modified metabolism can interfere with liver cell growth and distort a physiopathologic model [30].

Fah deficient mice also have inconveniences: their metabolic pathway leads to development of liver hepatocellularcarcinomas [82], requiring treatment by NTBC-diet repeated cycles to prevent tumor formation and maintain long-term survival. This diet cancels the natural selective advantage that triggers xenogenic cells proliferation and can give possible bias in results interpretation. To increase 
human hepatocyte repopulation efficiency, some teams use a transfection of uPA gene, which adds the same issues as encountered in $\mathrm{uPA}^{+/+}$model [27].

Another strategy is represented by liver suicide model: it consists to transfect recipient liver hepatocytes with an apoptotic gene; this gene being under the control of herpes virus type 1 thymidine kinase (HSV TK): it can be activated by administration of Gancyclovir, and thus could destroy specifically cells targeted with this suicide gene [83].

Hasegawa et al. [30] obtained an NOG (NOD/SCID/ Il2 $\mathrm{Rg}^{-/-}$) mouse expressing HSV TK transgene in their liver. By inducing apoptosis of liver recipient cells five days before transplantation of human hepatocyte, they observed a high index of repopulation (average up to $43 \%$ ), correlated with elevated human albumin in plasma, and functional human hepatocyte.

Douglas et al. [31] who used uPA-SCID model optimized it to achieve total replacement of $\mathrm{uPA}^{+/+}$hepatocytes by human hepatocytes, by associating mouse liver suicide to uPA-SCID model, so that Ganciclovir treatment could induce conditional selective murine hepatocyte death in humanized SCID-uPA mouse liver. But unexpected, mice survival was not increased by humanized liver, whatever the repopulation index ( 32 to $87 \%$ ).

As illustrated by the results of Douglas et al, the limits of the humanized liver reside intrinsically in the principle of xenogenic transplantation: whatever the models, even in the best repopulation performance such as $\mathrm{uPA}^{+/+}$or $\mathrm{Fah}^{-/-}$transgenic mouse, xenogenic murine models gave best engraftment results compared to human cells transplantation [29]. Interestingly, it does not seem possible to avoid a percentage of nearly complete failure of human cells engraftment in mouse liver, for each experiment, even in the studies reporting very high repopulation index $[28,79]$.

This disparity between animals of the same study could be due to imperfect immunosuppression [84] or inadequation between murine and human metabolism $[74,81]$.

In favor of the first hypothesis, Tateno et al. [85] showed that when human hepatocyte engraftment in uPASCID mouse results in more than 50\% repopulation, this high repopulation index leads to death of recipient. This mortality can be corrected by a treatment that blocks human complement factor activity.

In favor of the second hypothesis are the results of $\mathrm{Su}$ et al. [26] of a failure to induce chimerism in a $\mathrm{Fah}^{-/-} / \mathrm{Rag}^{-/-} / \mathrm{I} 2 \mathrm{rg}^{-/-}$mouse transplanted with human hepatocyte, in 6 over 14 mice despite an immunosuppressive drug (FK506). Also in favour of this hypothesis is the observation that mouse survival was not increased by humanized liver, whatever the repopulation index (32 to $87 \%$ ), in the uPA-SCID model of liver failure challenged with liver suicide gene activation [31]. There seems to be an incompatibility directly linked to animal species differences: although human and murine cells can create narrow cellular junctions, morphologically and architecturally subnormal links confirming integration of xenogenic cells but human cells will develop unexplained glycogen storage or steatosis anomalies $[81,86]$.
Therefore, the hypothesis that humanized liver would allow performing experiments not feasible on humans thus helping to predict pharmacotoxicological and pathobiological effects in humans needs additional demonstration. But, even in this case, transgenic models would mimic only limited aspects of human clinical liver failure, and one should be aware that humanized liver may not be transposable to real human physiology.

As a last comment, the use of an immunodeficient animal model could also be a bias in these liver cell transplantation studies. In fact, immune cells could modulate liver regeneration [87-89]. Their absence in immunodeficient animals could modify the liver response to acute injury (demonstrated by Strick-Marchand et al. [90]) and to chronic injury, as well as engraftment of hepatic cells. In the other hand, the use of immunosuppressive treatment for transplanted nonimmunodeficient animal models could also interact with liver physiology $[91,92]$ and become another bias.

This raises the question of the bias of using xenogenic models, with respect to the risk taken by xenogenic animal models not reflecting human physiology.

\section{Conclusion}

As a conclusion, Nude mice can sustain various liver injuries and are good recipients for xenogenic rodent hepatocyte transplantation. They remain an acceptable model for human hepatocyte engraftment and for human hepatic progenitor cell transplantation, by exploring the beneficial environment allowing the differentiation of the latter into mature hepatocyte as well as biliary cells. The low immunosuppressive background of nude mice is both an advantage, with easy breeding conditions, and disadvantage, with difficulties to raise humanized liver. They are certainly an interesting model to study liver regeneration mechanisms in a context of human clinical liver deficiency situations.

\section{References}

[1] I. W. Graziadei, "Living donor liver transplantation," Tropical Gastroenterology, vol. 28, no. 2, pp. 45-50, 2007.

[2] R. F. Saidi, N. Jabbour, Y. Li, S. A. Shah, and A. Bozorgzadeh, "Outcomes in partial liver transplantation: deceased donor split-liver versus live donor liver transplantation," $H P B$, vol. 13, no. 11, pp. 797-801, 2011.

[3] B. Carpentier and S. R. Ash, "Sorbent-based artificial liver devices: principles of operation, chemical effects and clinical results," Expert Review of Medical Devices, vol. 4, no. 6, pp. 839-861, 2007.

[4] R. D. Hughes, R. R. Mitry, and A. Dhawan, "Current status of hepatocyte transplantation," Transplantation, vol. 93, no. 4, pp. 342-347, 2012.

[5] Y. Yu, J. E. Fisher, J. B. Lillegard, B. Rodysill, B. Amiot, and S. L. Nyberg, "Cell therapies for liver diseases," Liver Transplantation, vol. 18, no. 1, pp. 9-21, 2012.

[6] S. Gupta and J. Roy Chowdhury, "Therapeutic potential of hepatocyte transplantation," Seminars in Cell and Developmental Biology, vol. 13, no. 6, pp. 439-446, 2002. 
[7] S. C. Strom, P. Bruzzone, H. Cai et al., "Hepatocyte transplantation: clinical experience and potential for future use," Cell Transplantation, vol. 15, no. 1, supplement, pp. S105-S110, 2006.

[8] M. Muraca, "Evolving concepts in cell therapy of liver disease and current clinical perspectives," Digestive and Liver Disease, vol. 43, no. 3, pp. 180-187, 2011.

[9] E. M. Sokal, "From hepatocytes to stem and progenitor cells for liver regenerative medicine: advances and clinical perspectives," Cell Proliferation, vol. 44, no. 1, supplement, pp. 39-43, 2011.

[10] L. Richert, C. Abadie, A. Bonet et al., "Inter-laboratory evaluation of the response of primary human hepatocyte cultures to model CYP inducers-A European Centre for Validation of Alternative Methods (ECVAM) - Funded pre-validation study," Toxicology in Vitro, vol. 24, no. 1, pp. 335-345, 2010.

[11] E. Alexandre, A. Baze, C. Parmentier et al., "Plateable cryopreserved human hepatocytes for the assessment of cytochrome P450 inducibility: experimental condition-related variables affecting their response to inducers," Xenobiotica, vol. 42, no. 10, pp. 968-979, 2012.

[12] H. Kamimura, N. Nakada, K. Suzuki et al., "Assessment of chimeric mice with humanized liver as a tool for predicting circulating human metabolites," Drug Metabolism and Pharmacokinetics, vol. 25, no. 3, pp. 223-235, 2010.

[13] S. C. Strom, J. Davila, and M. Grompe, "Chimeric mice with humanized liver: tools for the study of drug metabolism, excretion, and toxicity," Methods in Molecular Biology, vol. 640, pp. 491-509, 2010.

[14] M. Katoh and T. Yokoi, "Application of chimeric mice with humanized liver for predictive ADME," Drug Metabolism Reviews, vol. 39, no. 1, pp. 145-157, 2007.

[15] R. Kikuchi, M. McCown, P. Olson et al., "Effect of hepatitis C virus infection on the mRNA expression of drug transporters and cytochrome P450 enzymes in chimeric mice with humanized liver," Drug Metabolism and Disposition, vol. 38, no. 11, pp. 1954-1961, 2010.

[16] D. F. Mercer, "Animal models for studying hepatitis C and alcohol effects on liver," World Journal of Gastroenterology, vol. 17, no. 20, pp. 2515-2519, 2011.

[17] X. L. Zhou, G. J. Sullivan, P. Sun, and I. H. Park, "Humanized murine model for HBV and HCV using human induced pluripotent stem cells," Archives of Pharmacal Research, vol. 35, no. 2, pp. 261-269, 2012.

[18] I. Vidal, N. Blanchard, E. Alexandre et al., "Improved xenogenic hepatocyte implantation into nude mouse liver parenchyma with acute liver failure when followed by repeated anti-fas antibody (Jo2) treatment," Cell Transplantation, vol. 17, no. 5, pp. 507-524, 2008.

[19] J. A. Rhim, E. P. Sandgren, R. D. Palmiter, and R. L. Brinster, "Complete reconstitution of mouse liver with xenogeneic hepatocytes," Proceedings of the National Academy of Sciences of the United States of America, vol. 92, no. 11, pp. 4942-4946, 1995.

[20] D. Mahieu-Caputo, J. E. Allain, J. Branger et al., "Repopulation of athymic mouse liver by cryopreserved early human fetal hepatoblasts," Human Gene Therapy, vol. 15, no. 12, pp. 12191228, 2004.

[21] G. Nowak, B. G. Ericzon, S. Nava, M. Jaksch, M. Westgren, and S. Sumitran-Holgersson, "Identification of expandable human hepatic progenitors which differentiate into mature hepatic cells in vivo," Gut, vol. 54, no. 7, pp. 972-979, 2005.
[22] M. Joshi, B. Patil P, Z. He, J. Holgersson, M. Olausson, and S. Sumitran-Holgersson, "Fetal liver-derived mesenchymal stromal cells augment engraftment of transplanted hepatocytes," Cytotherapy, vol. 14, no. 6, pp. 657-669, 2012.

[23] D. H. Woo, S. K. Kim, H. J. Lim, J. Heo, H. S. Park, and G. Y. Kang, "Direct and indirect contribution of human embryonic stem cell-derived hepatocyte-like cells to liver repair in mice," Gastroenterology, vol. 142, no. 3, pp. 602-611, 2012.

[24] A. Banas, T. Teratani, Y. Yamamoto et al., "Rapid hepatic fate specification of adipose-derived stem cells and their therapeutic potential for liver failure," Journal of Gastroenterology and Hepatology, vol. 24, no. 1, pp. 70-77, 2009.

[25] L. Jiang, J. G. Li, L. Lan, Y. M. Wang, Q. Mao, and J. P. You, "Human hepatoma HepaRG cell line engraftment in severe combined immunodeficient $\times$ beige mice using mouse-specific anti-Fas antibody," Transplantation Proceedings, vol. 42, no. 9, pp. 3773-3778, 2010.

[26] B. L. Su, C. C. Liu, D. Xiang et al., "Xeno-repopulation of $\mathrm{Fah}^{-/-}$Nod/Scid mice livers by human hepatocytes," Science China Life Sciences, vol. 54, no. 3, pp. 227-234, 2011.

[27] H. Azuma, N. Paulk, A. Ranade et al., "Robust expansion of human hepatocytes in $\mathrm{Fah}^{-/-} / \mathrm{Rag} 2^{-/-} / \mathrm{Il} 2 \mathrm{rg}^{-/-}$mice," Nature Biotechnology, vol. 25, no. 8, pp. 903-910, 2007.

[28] M. Dandri, M. R. Burda, E. Török et al., "Repopulation of mouse liver with human hepatocytes and in vivo infection with hepatitis B virus," Hepatology, vol. 33, no. 4, pp. 981-988, 2001.

[29] D. Haridass, Q. Yuan, P. D. Becker et al., "Repopulation efficiencies of adult hepatocytes, fetal liver progenitor cells, and embryonic stem cell-derived hepatic cells in albumin-promoter-enhancer urokinase-type plasminogen activator mice," American Journal of Pathology, vol. 175, no. 4, pp. 1483-1492, 2009.

[30] M. Hasegawa, K. Kawai, T. Mitsui et al., "The reconstituted "humanized liver" in TK-NOG mice is mature and functional," Biochemical and Biophysical Research Communications, vol. 405, no. 3, pp. 405-410, 2011.

[31] D. N. Douglas, T. Kawahara, B. Sis et al., "Therapeutic efficacy of human hepatocyte transplantation in a SCID/uPA mouse model with inducible liver disease," PLoS ONE, vol. 5, no. 2, Article ID e9209, 2010.

[32] B. A. Croy, K. E. Linder, and J. A. Yager, "Primer for nonimmunologists on immune-deficient mice and their applications in research," Comparative Medicine, vol. 51, no. 4, pp. 300-313, 2001.

[33] Y. Shinkai, G. Rathbun, K. P. Lam et al., "RAG-2-deficient mice lack mature lymphocytes owing to inability to initiate $\mathrm{V}(\mathrm{D}) \mathrm{J}$ rearrangement," Cell, vol. 68, no. 5, pp. 855-867, 1992.

[34] J. A. Segre, J. L. Nemhauser, B. A. Taylor, J. H. Nadeau, and E. S. Lander, "Positional cloning of the nude locus: genetic, physical, and transcription maps of the region and mutations in the mouse and rat," Genomics, vol. 28, no. 3, pp. 549-559, 1995.

[35] D. Chatterjea-Matthes, M. E. García-Ojeda, S. DejbakhshJones et al., "Early defect prethymic in bone marrow T cell progenitors in athymic nu/nu mice," Journal of Immunology, vol. 171, no. 3, pp. 1207-1215, 2003.

[36] J. Fogh and B. Giovanella, The Nude Mouse in Experimental and Clinical Research, Academic Press, 1978.

[37] J. Fogh and B. Giovanella, The Nude Mouse in Experimental and Clinical Research, Academic Press, 1982.

[38] J. Dalmo, N. Rudqvist, J. Spetz, P. Laverman, O. Nilsson, and H. Ahlman, "Biodistribution of 177Lu-octreotate and 111Inminigastrin in female nude mice transplanted with human 
medullary thyroid carcinoma GOT2," Oncology Reports, vol. 27, no. 1, pp. 174-181, 2011.

[39] J. Fuchs, D. Schmidt, T. Pietsch, K. Miller, and D. Von Schweinitz, "Successful transplantation of human hepatoblastoma into immunodeficient mice," Journal of Pediatric Surgery, vol. 31, no. 9, pp. 1241-1246, 1996.

[40] J. M. Schnater, E. Bruder, S. Bertschin et al., "Subcutaneous and intrahepatic growth of human hepatoblastoma in immunodeficient mice," Journal of Hepatology, vol. 45, no. 3, pp. 377-386, 2006.

[41] Y. M. Wei, J. H. Lin, R. Xia, and J. C. Lan, "Establishment of a transplantable human myeloid BALB/c nude mouse model," Journal of Experimental Hematology, vol. 13, no. 4, pp. 596600, 2005.

[42] C. Yamamoto, H. Takemoto, K. Kuno et al., "Cycloprodigiosin hydrochloride, a new $\mathrm{H}^{+} / \mathrm{Cl}^{-}$symporter, induces apoptosis in human and rat hepatocellular cancer cell lines in vitro and inhibits the growth of hepatocellular carcinoma xenografts in nude mice," Hepatology, vol. 30, no. 4, pp. 894-902, 1999.

[43] M. Niemeyer, R. A. J. Oostendorp, M. Kremer et al., "Noninvasive tracking of human haemopoietic CD34+ stem cells in vivo in immunodeficient mice by using magnetic resonance imaging," European Radiology, vol. 20, no. 9, pp. 2184-2193, 2010.

[44] J. M. J. Aerts, B. Martinez-Madrid, J. L. M. R. Leroy, S. Van Aelst, and P. E. J. Bols, "Xenotransplantation by injection of a suspension of isolated preantral ovarian follicles and stroma cells under the kidney capsule of nude mice," Fertility and Sterility, vol. 94, no. 2, pp. 708-714, 2010.

[45] D. Guo, T. Fu, J. A. Nelson, R. A. Superina, and H. E. Soriano, "Liver repopulation after cell transplantation in mice treated with retrorsine and carbon tetrachloride," Transplantation, vol. 73, no. 11, pp. 1818-1824, 2002.

[46] S. Gupta, K. K. Bhargava, and P. M. Novikoff, "Mechanisms of cell engraftment during liver repopulation with hepatocyte transplantation," Seminars in Liver Disease, vol. 19, no. 1, pp. 15-26, 1999.

[47] R. H. Yuan, A. Ogawa, E. Ogawa, D. Neufeld, L. Zhu, and D. A. Shafritz, "p27Kip1 inactivation provides a proliferative advantage to transplanted hepatocytes in DPPIV/Rag2 double knockout mice after repeated host liver injury," Cell Transplantation, vol. 12, no. 8, pp. 907-919, 2004.

[48] S. Gupta, P. Rajvanshi, A. N. Irani, C. J. Palestro, and K. K. Bhargava, "Integration and proliferation of transplanted cells in hepatic parenchyma following D-galactosamine-induced acute injury in F344 rats," The Journal of Pathology, vol. 190, no. 2, pp. 203-210, 2000.

[49] E. Laconi, R. Oren, D. K. Mukhopadhyay et al., "Long-term, near-total liver replacement by transplantation of isolated hepatocytes in rats treated with retrorsine," American Journal of Pathology, vol. 153, no. 1, pp. 319-329, 1998.

[50] S. Laconi, S. Pillai, P. P. Porcu, D. A. Shafritz, P. Pani, and E. Laconi, "Massive liver replacement by transplanted hepatocytes in the absence of exogenous growth stimuli in rats treated with retrorsine," American Journal of Pathology, vol. 158, no. 2, pp. 771-777, 2001.

[51] R. Oren, M. D. Dabeva, P. M. Petkov, E. Hurston, E. Laconi, and D. A. Shafritz, "Restoration of serum albumin levels in nagase analbuminemic rats by hepatocyte transplantation," Hepatology, vol. 29, no. 1, pp. 75-81, 1999.

[52] M. Fujino, X. K. Li, Y. Kitazawa et al., "Selective repopulation of mice liver after fas-resistant hepatocyte transplantation," Cell Transplantation, vol. 10, no. 4-5, pp. 353-361, 2001.
[53] V. O. Mallet, J. M. Regimbeau, C. Mitchell, J. E. Guidotti, O. Soubrane, and H. Gilgenkrantz, "Liver repopulation: the selective advantage concept," Gastroenterologie Clinique et Biologique, vol. 26, no. 5, pp. 480-485, 2002.

[54] A. Mignon, J. E. Guidotti, C. Mitchell et al., "Selective repopulation of normal mouse liver by Fas/CD95-resistant hepatocytes," Nature Medicine, vol. 4, no. 10, pp. 1185-1188, 1998.

[55] C. Mitchell, V. O. Mallet, J. E. Guidotti, C. Goulenok, A. Kahn, and H. Gilgenkrantz, "Liver repopulation by Bcl-xL transgenic hepatocytes," American Journal of Pathology, vol. 160, no. 1, pp. 31-35, 2002.

[56] H. T. Lieu, F. Batteux, M. T. Simon et al., "HIP/PAP accelerates liver regeneration and protects against acetaminophen injury in mice," Hepatology, vol. 42, no. 3, pp. 618-626, 2005.

[57] H. T. Lieu, M. T. Simon, T. Nguyen-Khoa et al., "Reg2 inactivation increases sensitivity to Fas hepatotoxicity and delays liver regeneration post-hepatectomy in mice," Hepatology, vol. 44, no. 6, pp. 1452-1464, 2006.

[58] H. Malhi, A. N. Irani, I. Volenberg, M. L. Schilsky, and S. Gupta, "Early cell transplantation in LEC rats modeling Wilson's disease eliminates hepatic copper with reversal of liver disease," Gastroenterology, vol. 122, no. 2, pp. 438-447, 2002.

[59] E. P. Sandgren, R. D. Palmiter, J. L. Heckel, C. C. Daughterly, R. L. Brinster, and J. L. Degen, "Complete hepatic regeneration after somatic deletion of an albumin-plasminogen activator transgene," Cell, vol. 66, no. 2, pp. 245-256, 1991.

[60] J. A. Rhim, E. P. Sandgren, J. L. Degen, R. D. Palmiter, and R. L. Brinster, "Replacement of diseased mouse liver by hepatic cell transplantation," Science, vol. 263, no. 5150, pp. 1149-1152, 1994.

[61] K. Overturf, M. Al-Dhalimy, R. Tanguay et al., "Hepatocytes corrected by gene therapy are selected in vivo in a murine model of hereditary tyrosinaemia type I," Nature Genetics, vol. 12, no. 3, pp. 266-273, 1996.

[62] A. Gandillet, I. Vidal, E. Alexandre et al., "Experimental models of acute and chronic liver failure in nude mice to study hepatocyte transplantation," Cell Transplantation, vol. 14, no. 5, pp. 277-290, 2005.

[63] G. M. Higgins and R. M. Anderson, "Experimental pathology of the liver-I. Restoration of the liver of the white rat following partial surgical removal," Archives of Pathology, vol. 12, pp. 186-202, 1931.

[64] S. C. Strom, R. L. Jirtle, and R. S. Jones, "Isolation, culture, and transplantation of human hepatocytes," Journal of the National Cancer Institute, vol. 68, no. 5, pp. 771-778, 1982.

[65] F. G. Court, S. A. Wemyss-Holden, A. R. Dennison, and G. J. Maddern, "The mystery of liver regeneration," British Journal of Surgery, vol. 89, no. 9, pp. 1089-1095, 2002.

[66] J. Ogasawara, R. Watanabe-Fukunaga, M. Adachi et al., "Lethal effect of the anti-Fas antibody in mice," Nature, vol. 364, no. 6440, pp. 806-809, 1993.

[67] T. Suda, T. Okazaki, Y. Naito et al., "Expression of the Fas ligand in cells of T cell lineage," Journal of Immunology, vol. 154, no. 8, pp. 3806-3813, 1995.

[68] J. E. Guidotti, V. O. Mallet, C. Mitchell et al., "Selection of in vivo retrovirally transduced hepatocytes leads to efficient and predictable mouse liver repopulation," The FASEB Journal, vol. 15, no. 10, pp. 1849-1851, 2001.

[69] C. Kakinuma, K. Takagaki, T. Yatomi et al., "Acute toxicity of an anti-Fas antibody in mice," Toxicologic Pathology, vol. 27, no. 4, pp. 412-420, 1999.

[70] V. Lacronique, A. Mignon, M. Fabre et al., "Bcl-2 protects from lethal hepatic apoptosis induced by an anti-Fas antibody in mice," Nature Medicine, vol. 2, no. 1, pp. 80-86, 1996. 
[71] K. M. Braun and E. P. Sandgren, "Liver disease and compensatory growth: unexpected lessons from genetically altered mice," International Journal of Developmental Biology, vol. 42, no. 7, pp. 935-942, 1998.

[72] K. Yoshizato and C. Tateno, "A human hepatocyte-bearing mouse: an animal model to predict drug metabolism and effectiveness in humans," PPAR Research, vol. 2009, Article ID 476217, 11 pages, 2009.

[73] M. Grompe, "Therapeutic liver repopulation for the treatment of metabolic liver diseases," Human Cell, vol. 12, no. 4, pp. 171-180, 1999.

[74] T. C. Weglarz and E. P. Sandgren, "Timing of hepatocyte entry into DNA synthesis after partial hepatectomy is cell autonomous," Proceedings of the National Academy of Sciences of the United States of America, vol. 97, no. 23, pp. 1259512600, 2000.

[75] A. De la Coste, M. Fabre, N. McDonell et al., "Differential protective effects of $\mathrm{Bcl}-\mathrm{X}(\mathrm{L})$ and $\mathrm{Bcl}-2$ on apoptotic liver injury in transgenic mice," American Journal of Physiology, vol. 277, no. 3, pp. G702-G708, 1999.

[76] C. Mitchell, A. Mignon, J. E. Guidotti et al., "Therapeutic liver repopulation in a mouse model of hypercholesterolemia," Human Molecular Genetics, vol. 9, no. 11, pp. 1597-1602, 2000.

[77] I. Vidal, N. Blanchard, M. P. Chenard-Neu, P. Bachellier, B. Heyd, and F. Staedtler, "Increased survival despite failure of transplanted human hepatocyte implantation into liver parenchyma of Nude mice with repeated lethal Jo2 inducedliver deficiency," Cell Transplantation. In press.

[78] T. Kawahara, C. Toso, D. N. Douglas et al., "Factors affecting hepatocyte isolation, engraftment, and replication in an in vivo model," Liver Transplantation, vol. 16, no. 8, pp. 974-982, 2010.

[79] M. Katoh, C. Tateno, K. Yoshizato, and T. Yokoi, "Chimeric mice with humanized liver," Toxicology, vol. 246, no. 1, pp. 917, 2008.

[80] E. Robinet and T. F. Baumert, "Host and viral determinants for engraftment of virus permissive human hepatocytes into chimeric immunodeficient mice," Journal of Hepatology, vol. 53, no. 3, pp. 421-423, 2010.

[81] P. Meuleman, L. Libbrecht, R. De Vos et al., "Morphological and biochemical characterization of a human liver in a uPASCID mouse chimera," Hepatology, vol. 41, no. 4, pp. 847-856, 2005.

[82] K. D. Bissig, S. F. Wieland, P. Tran et al., "Human liver chimeric mice provide a model for hepatitis $\mathrm{B}$ and $\mathrm{C}$ virus infection and treatment," Journal of Clinical Investigation, vol. 120, no. 3, pp. 924-930, 2010.

[83] Y. Zhang, S. Z. Huang, S. Wang, and Y. T. Zeng, "Development of an HSV-tk transgenic mouse model for study of liver damage," FEBS Journal, vol. 272, no. 9, pp. 2207-2215, 2005.

[84] T. Kawahara, D. N. Douglas, J. Lewis et al., "Critical role of natural killer cells in the rejection of human hepatocytes after xenotransplantation into immunodeficient mice," Transplant International, vol. 23, no. 9, pp. 934-943, 2010.

[85] C. Tateno, Y. Yoshizane, N. Saito et al., "Near completely humanized liver in mice shows human-type metabolic responses to drugs," American Journal of Pathology, vol. 165, no. 3, pp. 901-912, 2004.

[86] R. A. Peterson, D. L. Krull, H. Roger Brown, and M. de Serres, "Morphologic characterization of phoenixBio (uPA $+/+$ / SCID) humanized liver chimeric mouse model," Drug Metabolism Letters, vol. 4, no. 3, pp. 180-184, 2010.
[87] Z. Dong, H. Wei, R. Sun, and Z. Tian, "The roles of innate immune cells in liver injury and regeneration," Cellular \& Molecular Immunology, vol. 4, no. 4, pp. 241-252, 2007.

[88] M. Fujiyoshi and M. Ozaki, "Molecular mechanisms of liver regeneration and protection for treatment of liver dysfunction and diseases," Journal of Hepato-Biliary-Pancreatic Sciences, vol. 18, no. 1, pp. 13-22, 2011.

[89] A. V. Tumanov, E. P. Koroleva, P. A. Christiansen et al., "T cellderived lymphotoxin regulates liver regeneration," Gastroenterology, vol. 136, no. 2, pp. 694-704, 2009.

[90] H. Strick-Marchand, G. X. Masse, M. C. Weiss, and J. P. Di Santo, "Lymphocytes support oval cell-dependent liver regeneration," Journal of Immunology, vol. 181, no. 4, pp. 27642771, 2008.

[91] A. C. A. Tannuri, U. Tannuri, M. C. M. Coelho, E. S. Mello, and N. A. S. R. Santos, "Effects of immunosuppressants on hepatocyte cell mitosis during liver regeneration in growing animal models of partial hepatectomy," Transplantation Proceedings, vol. 40, no. 5, pp. 1641-1644, 2008.

[92] U. Tannuri, A. C. A. Tannuri, M. C. M. Coelho, E. S. Mello, and N. A. S. R. Dos Santos, "Effect of the immunosuppressants on hepatocyte cells proliferation and apoptosis during liver regeneration after hepatectomy-Molecular studies," Pediatric Transplantation, vol. 12, no. 1, pp. 73-79, 2008. 


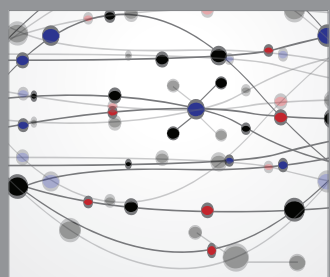

The Scientific World Journal
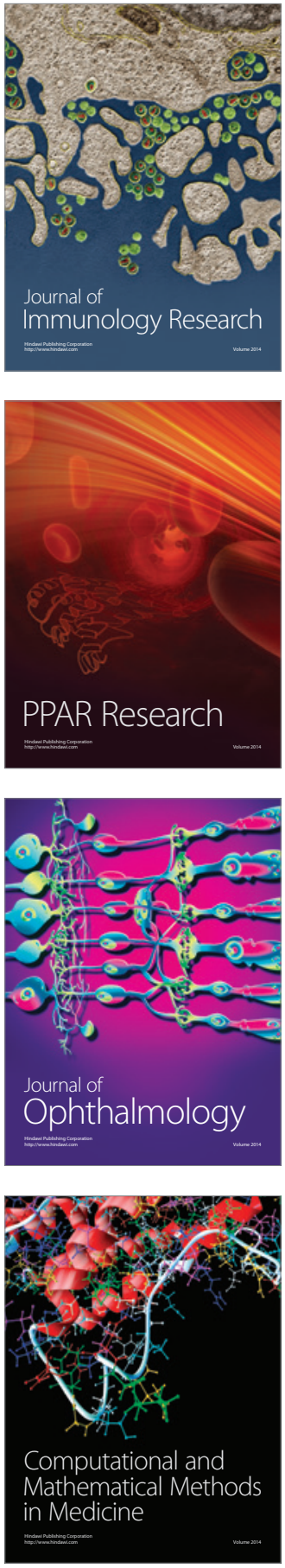

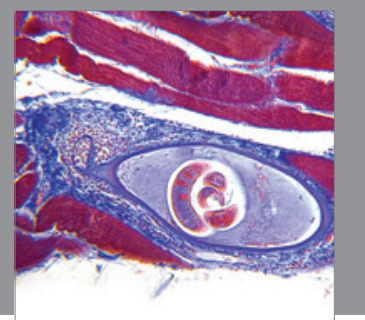

Gastroenterology

Research and Practice
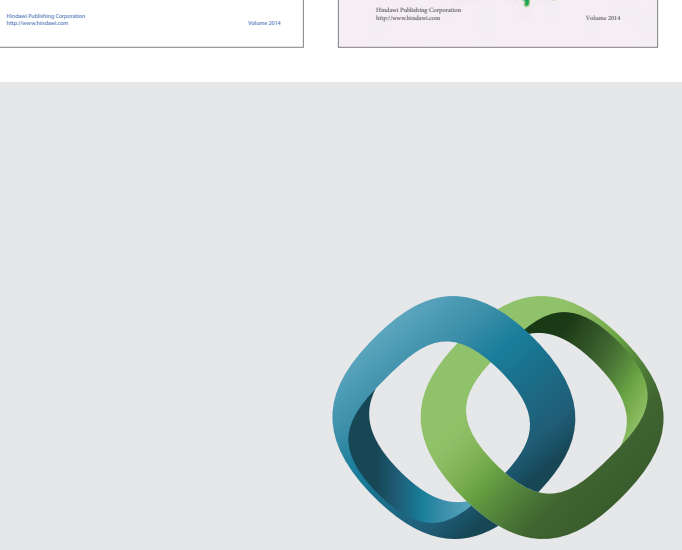

\section{Hindawi}

Submit your manuscripts at

http://www.hindawi.com
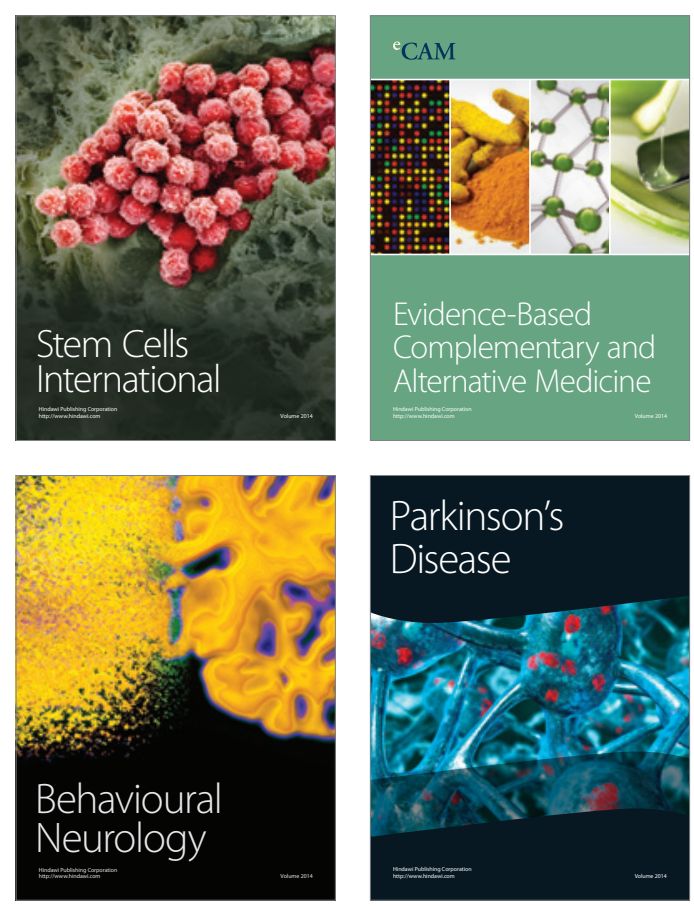

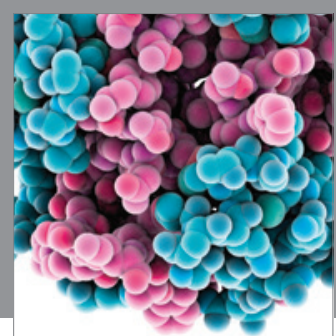

Journal of
Diabetes Research

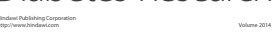

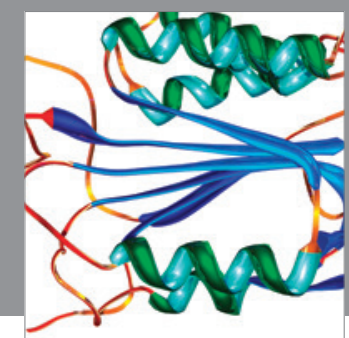

Disease Markers
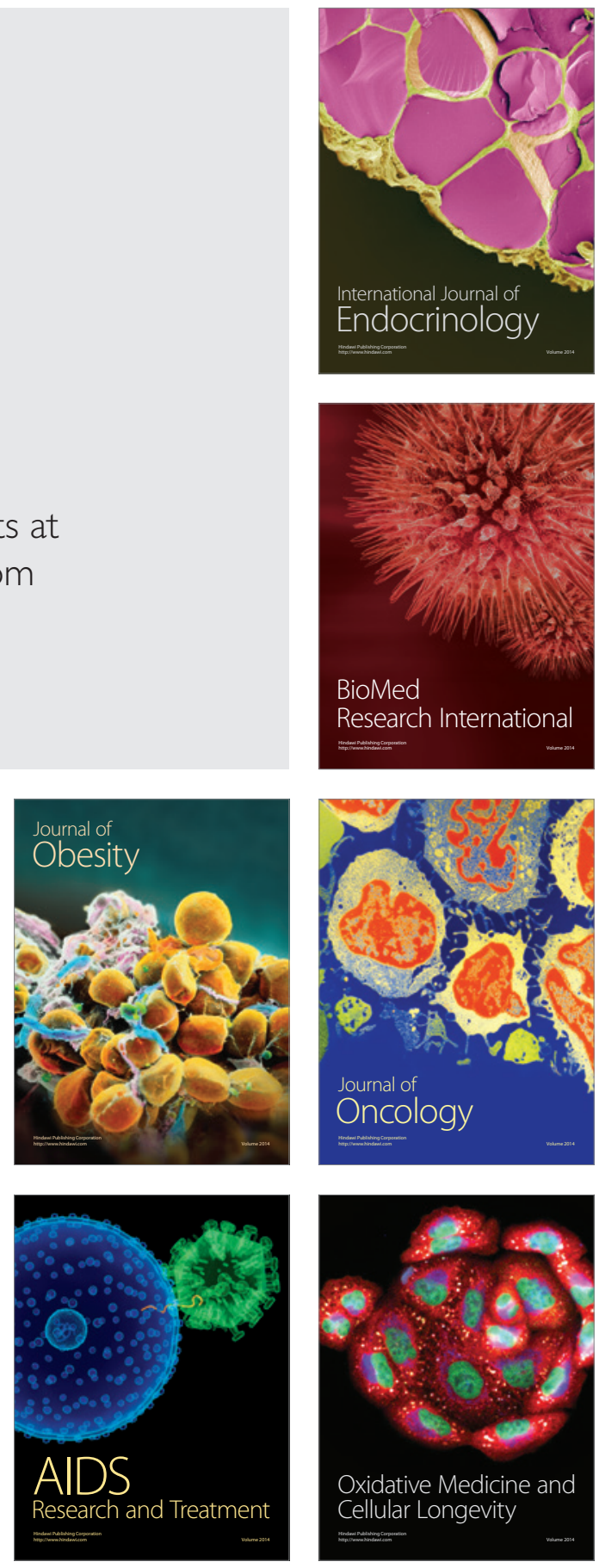